\title{
Controlled release formulations of herbicides based on micro-encapsulation
}

\author{
Fátima Sopeña ${ }^{1}$, Celia Maqueda, and Esmeralda Morillo \\ Instituto de Recursos Naturales y Agrobiología de Sevilla. Consejo Superior de Investigaciones Científicas \\ (CSIC). Reina Mercedes 10, Apartado 1052, 41080, Sevilla, España.
}

\begin{abstract}
F. Sopeña, C. Maqueda, and E. Morillo. 2009. Controlled release formulations of herbicides based on micro-encapsulation. Cien. Inv. Agr. 36(1): 27-42. Annual worldwide losses to weeds are estimated to comprise approximately $10-15 \%$ of attainable production among principal food sources. Worldwide consumption of herbicides represents $47.5 \%$ of the 2 million tons of pesticide consumed each year. However, the heavy use of herbicides has given rise to serious environmental and public health problems. It is therefore important to develop new herbicide formulations that are highly effective, that are safer (for the worker and for the environment), and that involve a low cost/production ratio. In this sense, controlled release formulations of herbicides have become necessary in recent years, since they often increase herbicide efficacy at reduced doses. The present work reviews in detail the components of various types of herbicide formulations, with an emphasis on controlled release formulations and micro-encapsulation.
\end{abstract}

Key words: Adjuvant, contamination, control, delivery system, formulations, herbicide, microencapsulation, weed control.

\section{Introduction}

As plants constitute the world's primary food source, there has been a tendency in recent years to maximize agricultural yields due to demographical growth. The increase in productivity has been achieved through the development of new high-yield crops, the heavy use of fertilizers and pesticides, and the use of heavy agricultural machinery. The benefits obtained through the use of these agricultural improvements are irrefutable. Several issues have engendered criticism; most notably, the environmental damage generated, including erosion,

Received 06 May 2008. Accepted 30 September 2008. 1'Corresponding author: sopenav@irnase.csic.es salinization and flooding of heavely irrigated soils, aquifer depletion, deforestation and environmental contamination due to the excessive use of pesticides.

Pesticides (plaguicides) include a wide variety of components and display a broad spectrum of chemical properties. For the purposes of $\mathrm{Co}$ dex Alimentarius (Commission created by the Food and Agricultural Organization [FAO]) and the World Health Organization (WHO: UNO, 1963), a plaguicide is any substance aimed to prevent, destroy, attract, repel or fight any plague, including unwelcome species of plants or animals; during production and/or storage, transportation, distribution and elaboration of food; agricultural products or food for animals; or that may be administered to animals to fight ectoparasites. The term includes herbicides and compounds used as growth regulators, insecti- 
cides, fungicides, defoliants, desiccants, and inhibitors of fruit thinning and germination.

The use of plaguicides is required, as plants are susceptible to approximately 100,000 sanitation problems, caused by a variety of agents, varying from region to region and depending on the dominant type of crop. In Africa, weeds are the main cause of agricultural losses, while diseases represent the most pressing agricultural issue in Latin America (Bifani, 1987). For instance, Rosales-Roble et al. (2005) found that, in only four weeks, wild sunflower (Heliantus annuss) caused losses of up to $26 \%$ in sorghum (Sorghum bicolor) production in Mexico.

At the global level, the annual losses due to the presence of destructive weeds are calculated to be around $10-15 \%$ of production among staple crops. There are currently 227 weed species identified to be responsible for $90 \%$ of damage to harvests, 18 of which are considered to be the most harmful worldwide (McDonald, 2002). Therefore, it is not unusual that $47.5 \%$ of the 2 million tons of pesticides consumed globally each year are herbicides (Gupta, 2004).

Herbicides are substances that partially or totally control weeds. Weeds always or predominantly grow in situations clearly altered by man, presenting undesirable effects at a specific time and place. According to Labrada et al. (1996) and Ware and Whitacre (2004), weeds generally: 1 . Hinder or alter the use of nutrients, water, light or useful space by the cultivated plants; 2 . Have a series of biological advantages favoring invasion (easy seed dispersal) and persistence (high level of seed production, long period of feasibility, stepwise germination, etc.) in cultivated zones; 3 . Release substances through the roots and leaves which are toxic to crops, as they inhibit or hinder germination, growth or development of nearby plants (allelopathy); 4. Create a favorable habitat for other proliferating plagues (arthropods, acari, etc.) by acting as a host; and 5. Hinder the normal harvest process and contaminate the production obtained.

Herbicides are required to control the biological and adaptive advantages of weeds. Thus, the development of formulations increasing the effectiveness and safety of these agrochemicals has become more relevant in recent years. The present work reviews the components as well as the types of herbicide formulations, with special emphasis on controlled release formulations based on micro-encapsulation.

\section{Environmental challenges deriving from the use of herbicides}

The presence of residual plaguicide in soil has many possible causes. Sometimes it is due to aerial treatments applied directly to the plant foliage in order to control pests and diseases, following which approximately $50 \%$ of the used product finally deposits in soil. In other cases, it occurs by plaguicide drift from the host by rain or wind. This is typically the case when applying insecticides, fungicides and herbicides. When applying some herbicides, the treatment is applied directly to the soil, resulting in a greater amount of residual herbicide. To a lesser degree, it may also derive from plant residues remaining in the soil after harvest. Finally, the drift by wind or rain from residues suspended in the atmosphere must also be considered.

There is public concern regarding the soil application of plaguicides since massive amounts are required to ensure a good harvest. Heavy plaguicide use can contaminate the environment, with serious risks for human health and natural ecosystems.

Residual plaguicide has been found in all environmental compartments (air, water and soil) and in all the geographical regions, including areas very remote to the original liberation site, such as oceans, deserts and polar zones (Berrada et al., 2003; Boparai et al., 2006; Konstantinou et al., 2006; Ribeiro et al., 2007). Likewise, residual plaguicide has been observed in organisms at all trophic levels, from plankton to whales and Arctic animals. These compounds bioaccumulate in numerous species and have been biomagnified through trophic nets. Human beings are not exempt from this contamination, and plaguicides have been identified in diverse human tissues and secretions (Barr and Needham, 2002), even in inhabitants of very 
isolated regions (Albert, 1998). In some studies conducted during the $1980 \mathrm{~s}$ and ' $90 \mathrm{~s}, 1-1.5$ million cases of serious intoxication due to these compounds were recorded (García, 1998).

Herbicides are applied in relatively high doses that are sometimes toxic, although toxicity dissipates with time in the field to concentrations below the level of minimal effectiveness. As a consequence, repeating the application is often necessary to control a plague (Scher, 1999; Fernández-Pérez, 2007). It must be taken into account that not all the plaguicides applied achieve their objective; when the plaguicides reach the soil surface, they may undergo a series of processes such as chemical and/or biological degradation, as well as photodecomposition. Losses due to runoff and lixiviation along the soil profile may also occur, yielding: (i) an increase in the residual activity of the herbicide, since the microbial activity responsible for the degradation of most herbicides decreases with depth; (ii) reduction of the concentration of herbicide in the uppermost soil layers to levels under the thresholds needed to control bad weeds, and subsequent accumulation in the root zone of the cultivation at levels presenting a danger to crops; (iii) contamination of underground waters by the water infiltrating the soil, which may carry herbicides through and under the root zone (Nègre et al., 1992; Carter, 2000; Dailey, 2004; Kudsk and Streibig, 2003; Boparai, 2006; Konstantinou et al., 2006; Baena and Martinez, 2006).

The aforementioned effect of losses due to runoff and lixiviation has led to the adoption of measures to protect the environment from the adverse effects caused by the use of plaguicides. FAO has promoted a collection of reasonable and responsible agriculture measures that have been defined as Good Agricultural Practices in the Use de Plaguicides (GAP), thus developing a code of international behavior for the distribution and use of plaguicides, and establishing standards to ensure that the application of phytosanitary products does not harm users, consumers or the environment (Codex Alimentarius, $\mathrm{FAO} / \mathrm{OMS}$ ).

However, it is necessary to recognize that plaguicides in general, and herbicides in particular, contribute significantly to sustain and protect crops and are thus essential for modern agriculture. However, despite the benefits of herbicide application, there is an urgent need to optimize use, not only as a response to standards for the maximum limits of plaguicide residuals in food and water, or to environmental contamination, but also to ensure that herbicides will continue as effective and valuable tools for farmers in the future (Kudsk and Streibig, 2003).

\section{Herbicide formulations}

Herbicides are rarely applied in the form in which they have been synthesized. Along with the active ingredient, substances are added (additives) to fulfill regulatory standards without diminishing the effectiveness of the active ingredients. Likewise, this active ingredient is combined with other materials (adjuvant) such as solvents, moisturizers and adherents. The product obtained constitutes the herbicide formulation, as usually commercialized (García Torres and Fernández-Quintanilla., 1991). Herbicide formulations have the following objectives (Tsuji, 2001; Mulqueen, 2003): (i). to obtain a high biological effectiveness, throughout the time required to control harmful weeds; (ii). to enable the management and application of herbicides; (iii). To reduce the use of solvents and/or select solvents that are dangerous or toxic; (iv). To minimize or avoid the adverse environmental effects on organisms that are not the cause for herbicide application (fish, crops, etc.); (v). To ensure safer use of herbicides by workers and users; (vi). To extend the range of herbicide application, and (vii). To be physically and chemically stable through time, and at the same time, compatible with other formulations that could be present in mixing systems of the application equipment.

The adjuvant/coadjuvant present in the herbicide formulations or during mixing in the tank of the application system are necessary to reach the objectives mentioned, as they are able to favorably modify the physical-chemical properties of the active ingredients (Zabkiewicz, 2000). The adjuvants may be classified as adjuvant activators or adjuvant modifiers, although many can be included in both categories (Covas, 2003). 


\section{Adjuvant activators}

Adjuvant activators increase the biological activity of the herbicide. The following are the main adjuvant activators:

Surfactants and their combinations. These are substances that reduce the surface tension existing between two surfaces that would otherwise repel each other. Surfactant improves the contact of herbicide solution drops on leaves, improving penetration (Seaman, 1990; Markus, 1996; Green and Beestman, 2007). The speed and total amount of herbicide penetrating the cuticle is related to the concentration and the chemical structure of the surfactant (Zabkiewicz, 2000). According to Seaman (1990), surfactants improve herbicide penetration primarily through solubilization, hygroscopic water retention, co-penetration, and modification of cuticle permeability.

Vegetal oils and minerals. Sometimes adding light oils to aqueous solutions of certain herbicides increases the foliar action of these products. Oils are normally mixed with emulsion or with tensoactive products (1-2\%), as they facilitate oil dispersal in water (Fernández-Quintanilla, 1991; Covas, 2003). Vegetal oils and minerals are used in $1 \%$ solutions, depending on the type of herbicide and oil. Oils may be mineral or vegetal in origin, such as oil derivatives or methylated vegetal oils (Covas, 2003).

Fertilizers. These are defined as any substance or chemical (organic or inorganic), natural or synthetic mixture contributing one or several nutritive elements essential for normal vegetative plant development. In addition, it has been observed that fertilizers containing ammoniacal nitrogen may increase the effectiveness of some herbicides, e.g., bentazone, dicamba, and glyphosate (Covas, 2003).

\section{Adjuvant modifier}

Adjuvant modifiers extend the conditions under which a plaguicide formulation, and an herbicide formulation in particular, becomes useful. This group includes:
Antifoaming. Antifoaming modifiers are added to the suspension of a plaguicide to reduce the problems caused by the formation of excess foam during application. The most frequent mode of action involves reducing the surface tension, leading to a physical destabilization of foam bubbles. This group includes oils, alcohols, malic acid and tartaric derivatives (Green and Beestman, 2007).

Coating agents used to treat seeds. Recent research on seed-protecting treatments has illustrated the importance of this technique. In the case of herbicides, these treatments consist in coating seeds with herbicides highly tolerant to cultivation, using specific coating agents such as silicone gels or polymers indissoluble in water (Green and Beestman, 2007).

pH modifier. These coadjuvants are used to increase or decrease the $\mathrm{pH}$ of the solution because many plaguicides may become inactive at extreme pH (Covas, 2003). For example, the herbicide glyphosphate is currently offered at a $\mathrm{pH}$ lower than 2.0, as mono-sal at $\mathrm{pH}$ 4.4-5.0, and as di-sal at neutral $\mathrm{pH}$ close to 6.7. The herbicide particles must dissolve rapidly in order to penetrate the leaf's waxy cuticle. A pH increase in the spray tank, over the pKa of a weak acid-type herbicide, converts the herbicide to an anionic form, which allows it to dissolve easily. In addition, the $\mathrm{pH}$ increase must increase the biological activity of the herbicide when solubility is limiting, in circumstances where the pulverization volume is low or where there is a high concentration of that herbicide. When the solubility of a weak acid is not limiting, a low $\mathrm{pH}$ allows it to reach a neutral form that may penetrate more rapidly in the membranes and lipophilic cuticles of the plants (Green and Beestman, 2007).

The decision regarding the type of formulation to be used must take into consideration the physical-chemical properties of the herbicide, the application of the formulation (foliar vs. soil), the type of crop, the agricultural practices, the biological properties of the herbicide (selectivity, transportation, toxicity in mammals and in other organisms), and economic factors (Markus, 1996). Likewise, the requirements of the plaguicide industry with regard to safety, ef- 
fectiveness, cost and feasibility of application of the plaguicide compounds must be taken into account (Tsuji, 2001; Rüegg et al., 2007).

The main types of conventional formulations of herbicides are presented in Table 1. The first three classes may be considered as classic types of formulations, while the following were designed more recently to address the disadvantages of the first three (Mulqueen, 2003). Emulsionable concentrates (EC) are preferred for certain active ingredients - liquids or solids with a low point of fusion and/or that are insoluble in water and need to be applied in the field with water. Herbicides with low solubility or solids with a high point of fusion are formulated as moisturizing powders (MP), water dispersable granules (WG) or suspension concentrates (SC) (Seaman, 1990; Mulqueen, 2003). Likewise, suspensionsemulsions (suspoemulsions) (SE) are useful to combine several types of compounds in a single formulation (Mulqueen, 2003).

Although sometimes the conventional formulations may be incorporated directly as solids (powders or granules), they are generally dispersed or diluted in water to be applied as a spray on the crops and/or soil; therefore, the active ingredients are immediately incorporated into the medium (Scher, 1999; Mulqueen, 2003). This situation causes problems of toxicity and environmental contamination in agricultural areas where conventional formulations are applied, as a consequence of the high doses necessary to compensate for losses resulting from chemical and/or biological degradation, photodecomposition, volatilization, absorption by plants and adsorption to soil colloids, runoff and lixiviation, among others (Markus, 1996; Scher, 1999; Geisler et al., 2004). These formulations also represent risks for the workers, including eye irritation, absorption through skin and inhalation (Tsuji, 2001).

Systems of controlled liberation (SCL) represent an alternative to the conventional systems of herbicide application. This process is defined as "a technique or method where the active agent is available for a specific product to a speed and duration designed to achieve the intended effect" (Scher, 1999). The herbicide SCL may be defined as a technology wherein an ac- tive ingredient is available for a specific goal at a concentration and with a duration designed to achieve the intended effect, aiming to reach optimal biological effectiveness and to reduce any harmful effects (Rüeg et al., 2007; Undabeytia et al., 2003; Fernández-Pérez, 2007). Reducing herbicide levels also reduces costs for farmers as well as for companies (Markus, 1996). SLCs offer additional advantages (Mulqueen, 2003; Sopeña et al., 2007; Sopeña et al., 2007a; 2008a): (i). They may reduce herbicide loss due to lixiviation, volatilization, drift and degradation in soils. (ii). They may reduce phytotoxicity. (iii). They may facilitate herbicide management and safer applications, reducing toxicity in humans. (iv). They offer the possibility to act more selectively on the intended target. (v). They increase the duration of activity and the effectiveness of the active ingredient, in soil as well as at the foliar level. (vi). They allow the inclusion of reactive substances in the same formulation.

Many of the advantages mentioned above stem from SLC liberation of the active ingredient, ensuring availability at the optimal time for cultivation protection, without rapid migration of the active ingredient due to precipitation or irrigation. Many studies have investigated the preparation of controlled plaguicide liberation formulations (Nelson and Penner, 2007; Fernández-Pérez et al., 2005; Vasilakoglou et al., 2001; Undabeytia et al., 2004; Sopeña et al., 2007b; 2008a), as well as the kinetics of liberation in water (Fernández-Urrusuno et al., 2000; Zhao and Wilkins, 2000; Pérez-Martínez et al., 2001; Zhu and Zhuo, 2001; Sopeña et al., 2005; Garrido-Herrera et al., 2006).

As seen in Figure 1, the rate at which the active ingredient is liberated from the conventional formulations is generally related exponentially to the amount (or concentration) of the ingredient that remains in the formulation. This means that the concentration in the environment must initially be very high (usually toxic), consequently decreasing rapidly to low and ineffective levels. In contrast, SLCs generally exhibit low initial concentrations of active ingredient that remain stable long enough to protect the crop. Alternately, they may rapidly release high initial concentrations of the active ingredient, but then decrease release enough to maintain 
Table 1. Types of conventional herbicide formulations [(Extracted and modified by Mulqueen (2003) and Cover (2003)].

\begin{tabular}{ll}
\hline Type & Description \\
\hline Solutions (S) & Oily or aqueous solutions and surfactants to improve uptake into plants \\
Emulsifiable Concentrate (EC) & $\begin{array}{l}\text { Oily or aqueous solution of an active ingredient (a.i.) plus emulsifiers to } \\
\text { facilitate its solubility }\end{array}$ \\
Wettable power (WP) & $\begin{array}{l}\text { Solid active (50-80\%) plus wettable and dispersant agents } \\
\text { Suspension Concentrate (SC) }\end{array}$ \\
$\begin{array}{l}\text { Solid (a.i.)/liquid dispersal } \\
\text { Concentrated emulsion of a lipophilic a.i. with low melting point. Oil-in-water } \\
\text { emulsion or water in oil emulsion }\end{array}$ \\
$\begin{array}{l}\text { Mixture of CE (O/W) plus SC. } \\
\text { Eultiple Emulsions }\end{array}$ \\
$\begin{array}{l}\text { Emulsion that can be emulsified in other external phase types: oil-in-water-in- } \\
\text { oil (O/W/O) or water-in-oil-in-water (W/O/W). } \\
\text { a.i. is adsorbed or coated by inert material plus dispersible agent, which is } \\
\text { quickly dispersed into water }\end{array}$
\end{tabular}

effective levels for a prolonged length of time (Scher, 1999; Collet and Moreton, 2004). Therefore, the main advantage of SLCs is the use of less active ingredient for the same period of activity.

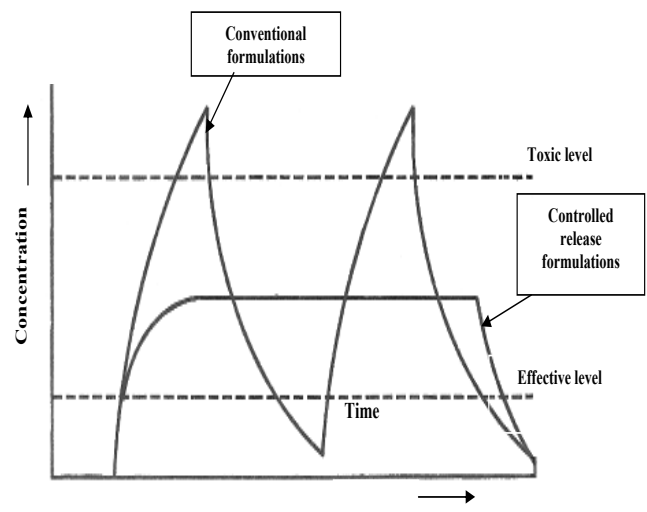

Figure 1. Herbicide concentrations resulting from conventional and controlled release formulations.

If the application of SLC to a certain crop is advisable, it must be determined which type of SLC is the most appropriate. The selection of one or the other will depend on the physicalchemical characteristics of the herbicide, the crop needs, the characteristics of the place where it will be applied and the characteristics of the application devices. The SLC chosen should allow rapid, evenly distributed treatment to be applied to large areas of cultivation (Wilkins, 1990; Scher, 1999).

Based on the classification by Wilkins (1990), there are four big groups of LC systems:

(i). Reservoir systems covered with speed-controlling membranes. This type of system consists of a polymeric membrane surrounding a reservoir, where the active ingredient (pure or saturated within the reservoir) is in the form of solid particles, liquid droplets or a solid dispersal in liquid. The membrane isolates and protects the core content from environmental degradation and from interaction with other materials (Arshady, 1999a). The membrane controls the speed with which the active ingredient extends throughout the system, so it must become permeable, for example, by hydration or by solubilization of the active ingredient in some components of that membrane. In turn, the polymer must remain intact during the period of liberation, without swelling or undergoing erosion (Collet and Moreton, 2004). This applies to micro- and macro-capsules, as well as other types of coated systems (Wilkins, 1990).

The osmotic pump system is a variant of the membrane-controlled system, which is composed of a reservoir surrounded by a semipermeable membrane. This membrane allows water flow toward the core, which dissolves. 
When the core dissolves, hydrostatic pressure pushes the solution or suspension of the active ingredient through the hole made in the envelope. The liberation speed will depend on the speed of water flow through the membrane and on how fast the solution or suspension of the active ingredient emerges from the hole (Collet and Moreton, 2004).

(ii). Reservoir system without speed-controlling membranes. Hollow fibers are the simplest example; the active ingredient spreads throughout the internal cavity, which may extend through the surrounding walls (if the ends are sealed) or, alternately, through one or both ends (Wilkins, 1990; Scher, 1999). Other systems like foams and porous polymeric substrates have potential for use in the control of plagues (Wilkins, 1990).

(iii). Monolithic systems. In this type of system, the active ingredient is dissolved or dispersed in an inert polymeric or elastomer matrix until saturation. As the active ingredient is liberated from the monolithic system, more active ingredient spreads to the surface exterior, as a response to the decreasing concentration gradient. If the material used to form the matrix is engineered to be soluble or degradable during use, it is said that the monolithic device is erosionable. In this case, liberation of the active ingredient proceeds via diffusion and liberation due to matrix erosion (Wilkins, 1990; Scher, 1999).

The fundamental difference between a membrane system and a matrix system is that, in the first, the membrane is located only on the surface of the system; in the second, the polymer occupies the entire system. These systems may be divided in two groups: 1) those where the active ingredient is dispersed in a soluble matrix that liberates the active ingredient when dissolving, or when swelling and dissolving (hydrophilic colloid matrices); 2) those where the active ingredient is dispersed in an insoluble matrix, from which it is liberated when a solvent penetrates the matrix and dissolves the particles (lipid matrices and insoluble polymers) (Collet and Moreton, 2004).

(iv). Laminate structures. These are multilaminate systems where the central lamina is loaded with the active ingredient and where there are other external laminae at each side, protecting it, and also regulating liberation of the active ingredient (Wilkins, 1990; Scher, 1999).

Finally, other types of SLC systems involve adsorption mediated by ionic interchange on resins. In these systems, the active ingredient interacts with the resin of ionic interchange, forming a complex through substitution of hydrogen atoms. The complex formed may be susceptible to encapsulation or suspension in an aqueous medium. Liberation of the active ingredient from the complex will depend on $\mathrm{pH}$ and on the concentration of electrolytes in the medium (Ansel et al., 1999).

\section{What is micro-encapsulation?}

Micro-encapsulation is defined as the process of coating an active substance (molecules, solid particles or liquid globules consisting of various materials), resulting in particles of micrometric size. The products resulting from this technological process are denoted as microparticles, microcapsules (MICs), or microspheres (MISs), according to system particularities with regard to morphology and internal structure; all are $<1$ mm (Remuñán López and Alonso Fernández, 1997). When these particles are smaller than $1 \mu \mathrm{m}$, they are called nanocapsules or nanospheres to emphasize their small size. In practice, many of these particles are not spherical, although they are still considered as MIC or MIS due to their size and composition. Therefore, the terms microparticles and nanoparticles are used in a general way to denote particles presenting either irregular or spherical shape (Arshady, 1999a, 1999b).

MIS are defined as particles that are spherical and of micrometric size (between 1-1000 $\mu \mathrm{m}$ ). However, in practice, the term microspheres is also used for particles ranging in size from 0.02-2000 $\mu \mathrm{m}$ (Arshady, 1999b). Externally, MICs are similar to MISs, but the microcapsules are composed of one or more active ingredients (core) and a protecting matrix (wall or cover). The matrix or protecting layer is normally an organic polymer, although it can 
also be an inorganic polymer, or even metal. The active ingredient may be solid or liquid, or even gas. Likewise, the active material may be in the form of a central core surrounded by an inert polymer (MIC-type reservoir or mononuclear) or finely dispersed in a polymeric matrix (MIC-type monolithic); alternately, it may present an intermediate morphology (polynuclear MIC) (Arshady, 1999a; Arshady 1999b; Scher, 1999). The typical structures of different types of microparticles are shown schematically in Figure 2.

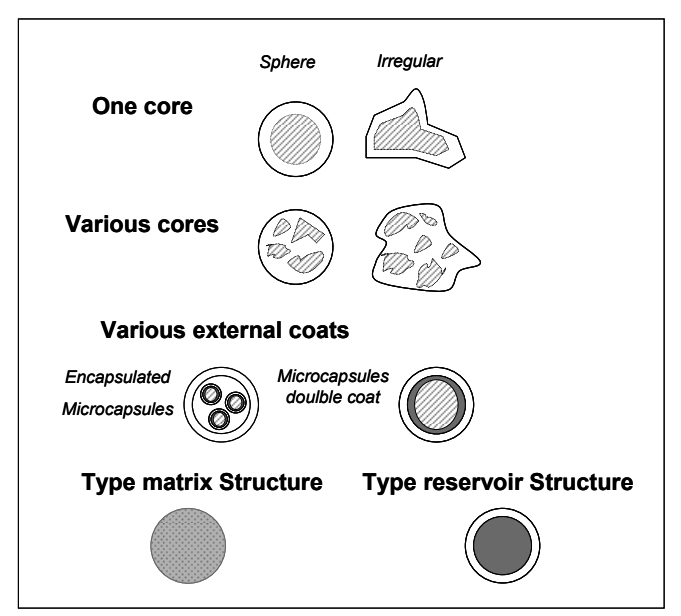

Figure 2. Micro-particle structure.

Notably, there is a third type of microparticles, formed by lipids or lipoid surfactants forming vesicles in solution. The vesicles have a double lipid layer containing an aqueous compartment, analogously to cell membranes; they are thus considered as cell membrane prototypes. If these vesicles are formed by phospholipid surfactants, they are called liposomes. Liposomes may be considered as a special case of microcapsules, whose walls are phospholipids. Their size is generally between $50-500 \mathrm{~nm}$, although they may reach $5 \mu \mathrm{m}$. Liposomes may be unilaminar, when the active agent, normally in aqueous phase, is inside the vesicle constituted by the phospholipidic membrane. Liposomes are multilaminar when there are successive layers of active substance and phospholipid membranes (González-Rodríguez et al., 2007). There is a wide range of amphipathic lipids that may be used to prepare liposomes, although the fact that a specific lipidic molecule presents a high degree of surface activity does not guarantee the formation of a "bilayer"-type structure in the presence of water. The interactions with the neighboring molecules and water, as well as the relation between the surface area of its polar head and its hydrophobic tail, will determine the physical structure of the vesicle. For example, lipids such as phosphatidylcholine or phosphatidylserine usually result in bilayers (González-Rodríguez et al., 2007; Mura et al., 2007), while the lisophospholipids form monolayers, resulting in simple vesicles or micelles.

Anionic herbicide formulations have recently been designed that involve encapsulation in vesicles formed by alkylammonium cations with long alkylic chains. The vesicles containing the herbicides allow for adsorption of the molecules contained, a process mediated by electrostatic interactions in montmorillonite (Undabeytia et al., 2003; 2004).

\section{Plaguicide micro-encapsulation}

Plaguicide encapsulation aims to control the liberation of the formulation's active ingredients, to enable their their use for a specific purpose at an intended concentration, to diminish the disadvantages of the active ingredient, and to maintain the highest possible biological effectiveness. Recently, Green and Beestman (2007) published a review on the formulations of patented and commercialized agrochemicals; they pointed out that most of the controlled liberation products comprise technologies based on micro- and nano-encapsulation. This may be because herbicide micro-encapsulation reduce losses of the active ingredients (Wilkins, 1990; Tsuij 2001). In addition, there are studies reporting an improvement in persistence and a reduction in herbicide losses due to lixiviation (Johnson and Pepperman, 1996; Gerstl et al., 1998; Vasilakoglou et al., 2001; Vasilakoglou and Eleftherohorinos, 2003; Fernández-Pérez et al., 2005; Sopeña et al., 2007a; 2007b).

Among the first studies evaluating the effectiveness of microencapsulated herbicides, Schreiber et al. (1993) and Mills and Thurman (1994) studied the loss of atrazina due to lixiviation and concluded that micro-encapsulation diminishes 
the contamination of underground waters in the context of low levels of herbicide lixiviation. Likewise, research shows that there is a greater reduction of herbicide volatilization with the microencapsulated formulations as compared to the commercial formulations, thus diminishing the presence of herbicide in the atmosphere (Wienhold and Gish, 1994; Dailey, 2004).

On the other hand, it has been observed that plaguicide micro-encapsulation has also reduced phytoxicity in crops (Bernards et al., 2006). Micro-encapsulation has been proven to improve plaguicide effectiveness in comparison to commercial formulations (Greene et al., 1992; Vasilakoglou and Eleftherohorinos, 2003; Hatzinikolau et al., 2004, Sopeña et al., 2007a; 2008b). This improvement is attributed to herbicide liberation from the micro-encapsulated formulations in a slow and controlled manner of release to the soil solution, which allows effective control of harmful weeds for a longer period of time (Sopeña et al., 2007a; 2007b).

However, it is noteworthy that micro-encapsulation implies, in some cases, the use of unwanted toxic substances and/or processes of long duration (Riggle and Penner, 1988; Greene et al., 1992; Gan et al., 1994; Vailakoglou et al., 2001). In addition, the results may vary depending on the experimental conditions and type of technique and on the herbicide and polymer used to provide the microparticles (Fleming et al., 1992; Nègre et al., 1992; Wienhold and Gish, 1994; Gerstl et al., 1998).

\section{Materials used in herbicide microencaps- ulation}

The biodegradation of formulation materials is also an important aspect related to the controlled liberation of plaguicides for environmental applications (Lohmann, 1992). Biodegradation is understood as the destruction and assimilation of organic compounds by living organisms and their enzymes, particularly by bacteria and fungi (Scher, 1999). Aminabhavi et al. (1990) define biodegradation as the sum of microbial processes resulting in mineralization of organic compounds. Therefore, degradation in the envi- ronment is the result of the combination of light, water, heat, insects, oxidation, other contaminants, microorganisms, animals and mechanical forces such as wind, rain, wave action, sand and vehicle traffic (Scher, 1999). However, considering only the effects of soil microorganisms, polymers or biodegradable materials may be defined as those compounds formed by macromolecules susceptible to damage in biologically active environments. Therefore, they must have functional groups accessible to enzymes, which are also susceptible to non-biological types of degradations, such as hydrolysis, reduction or photodegradation, among others (Wilkins, 1990).

Wilkins (1990) first classified the materials used in encapsulation according to their degree of biodegradation: (i). Starch and systems based on amylose. (ii). Other polysaccharides (cellulose and derivatives, chitin, chitosan, dextran, alginate). (iii). Proteins (casein, albumin, gelatin). (iv). Lipophilic materials (rubbers and waxes). (v). Synthetic polymers (polyvinyl alcohol, polylactato, polyglycolato, other polyesthers, polyamines, polyamide-type acids, polyacrylamide). (vi). Miscellaneous (polyhydroxybutirato, tannins, polyhydroxyvalerato) lignins, resins and biopolymers modified by substitution, "crosslinking" or "grafting". Among all these biodegradable materials, the lignin polyphenolic macromolecule is the most abundant in ground plants. The macromolecule protects plants from light, water and microorganisms, degrading more slowly than polysaccharides.

Unmodified starch is an efficient matrix for encapsulating solid and/or liquid active ingredients. Formulations encapsulated with starch have been widely used for herbicides such as atrazine, alachlor and metolachlor (Mills and Thurman, 1994). Starch may also be modified, due to the inherent advantages of the new matrix. Starch may be copolymeralized with vinylic and/or acrylic monomer (Zhu and Zhuo, 2001).

The Kraft type of lignins has also been used for the controlled liberation of a great number of plaguicides including: metribuzine, alachlor, carbofurano, and cloroambeno (Wilkins, 1990; Cotterill and Wilkins, 1996; Zhao and Wilkins, 2003). The use of additives soluble in water at 
the matrix phase also influences the liberation kinetics. For example, the addition of urea increased the degree of liberation of diuron in lignine matrices (Cotterill and Wilkins, 1996). The rapid dissolution of urea creates a porous structure, increasing the penetration of water inside the lignin granules.

The formulations with alginates are based on the ability of alginate to form gels after the addition of a polyvalent cation, which interacts with the alginate carboxyl groups. The liberation profile of the plaguicide may be modified by the incorporation of adsorbents during the gelification process. Clays, silica, aluminum oxide and coal are the most frequently used adsorbents, resulting in greater control of the degree of liberation (Gan et al., 1994; Johnson and Pepperman, 1996; Villafranca-Sánchez et al., 2000; Garrido-Herrera et al., 2006). In controlled liberation formulations prepared with alginates, the liberation of the herbicide is slower when clays are incorporated in the formulation. If active coal is also incorporated, the liberation is delayed even more in comparison to the alginate-clay and commercial formulations. According to Garrido-Herrera et al. (2006), the sorption capacity of the formulation components and the formulation permeability determine the slow speed of liberation.

Some cellulose derivatives are also used as matrices for the controlled liberation of plaguicides. Although their use and development is not as extensive as the derivatives from lignin or starch, the cellulose derivatives are good materials for this type of formulation because they are biodegraded via hydrolysis by the enzyme cellulase, which is produced by bacteria and fungi (which are very abundant in natural media). Some of these derivatives are soluble in water or unstable, requiring insolubilization or stabilization during the synthesis of the macromolecular chain through "crosslinking" or by the addition of certain substances. For example, carboxymethylcellulose has been stabilized with gelatin (Prasad and Kalyanasundaram, 1993) and with aluminum (Kök et al., 1999). The effectiveness of several herbicides encapsulated in different cellulose polymers has been investigated previously (Dailey et al., 1993; Dailey and Dowler, 1998). The results depended on the type of herbicide and polymers used. The polymers show- ing the greatest effectiveness were cellulose acetate butyrate (CAB) and the ethylcellulose in MICs of atrazine and metolachlor. On the contrary, MICs of metribuzine demonstrated effectiveness comparable to the commercial formulation, while those formulations of cyanazine and $\mathrm{CAB}$ were less active than the commercial formulation. Likewise, it has been observed that the use of alachlor formulations micro-encapsulated in ethylcellulose (EC) was efficient in reducing the herbicide losses due to volatilization (Dailey, 2004). More recently, it has been found that alachlor and norflurazon formulations control liberation. Microencapsulated in EC, they reduce mobility (Sopeña et al., 2007a; 2007b) and protect herbicides against degradation in the soil-water system (Sopeña et al., 2007a), regardless of the type of soil involved (Sopeña et al., 2008a). These characteristics result in greater herbicide activity than that observed with the commercial formulation (Sopeña et al., 2007a). In particular, Sopeña et al. (2008b) found that, through time, the alachlor encapsulated in EC is more effective in comparison to the commercial formulation, other microencapsulated alachlor formulations, (Petersen et al., 1988; Vasilakoglou and Eleftherohorinos, 1997; Dowler et al., 1999) and acetochlor (Parker et al., 2005).

The polymers used for plaguicide micro-encapsulation must satisfy the following conditions (Tsuji, 2001): 1. They must exhibit molecular weight, temperature of vitreous transition and molecular structure adequate to allow sufficient liberation. 2. They should not react with plaguicides. 3 . The polymer and its degradation products should not cause any type of environmental contamination. 4 . They must be generally stable during their use and storage, and they must also be easily manufactured and fabricated in order to achieve a desirable product at low cost.

In the case of MICs, the substances more commonly used as plaguicide coating are polyurea, polyamida, melamine resin, nylon, and gelatin (Scher, 1999). Likewise, in the 1980s, the development and use of molecular encapsulations with cyclodextrin began. With this technique, some complexes of inclusion form between two or more molecules (one is the host molecule, and the other is the guest molecule [the plaguicide]) (Szejtli, 1982). Cyclodextrins may trap a great 
variety of molecules comprising one or two benzene rings, or even longer molecules with a chain of comparable size, forming complexes of inclusion (Szejtli, 1988). The encapsulations with cyclodextrins have the aforementioned advantages for controlled liberation formulations and also increase the solubility of certain not very soluble plaguicides and, therefore, their availability in the soil solution (Ginés et al., 1998; Morillo et al., 1998; Morillo, 2006; Pérez-Martínez et al., $2000 \mathrm{a}$ and $\mathrm{b}$ ). This is because cyclodextrins exhibit high solubility in water because they have free hydroxyl groups on the external surface of the ring, rendering the internal cavity slightly nonpolar. There are diverse applications for the cyclodextrins and plaguicide complexes of inclusion. Thus, Kamiya et al. (1994) have shown that including $\beta$-cyclodextrine $(\beta-C D)$ inhibits photodegradation. The increased availability of compounds such as p,p-DDT following encapsulation with cyclodextrins has been proposed as a method for recovering contaminated soils (Wang and Brusseau, 1993). Villaverde (2007) showed the effectiveness of a $\beta-C D$ solution as a tool for the in situ extraction of norflurazon herbicide prior to soil bioremediation. The values of the hysteresis coefficient were reduced by 2,4-D desorption in soils due to the use of $\beta-C D$, as compared to the use of water (PérezMartínez et al., 1999).

Finally, it is necessary to point out that the type of encapsulated plaguicide and its functional groups have great influence on the degree of liberation of that plaguicide, due to the energy of the chemical link established between the matrix and the plaguicide, as well as the feasibility of its solubilization. The greater the solubility of a plaguicide is, the lower the $T_{50}$ value. The coefficient of octanol-water partition of a plaguicide $\left(\mathrm{K}_{\mathrm{ow}}\right)$ is also a good factor to predict the $\mathrm{T}_{50}$ value and the degree of liberation; the higher the Kow is, the slower the liberation, as the affinity of the plaguicide for the organic phase (lignin, starch, cellulose, etc.) is higher than with water. Most of the microencapsulated plaguicides are insecticides, while others are herbicides, insect repellents or plant growth regulators. This fact is related to the mechanism of plaguicide action and the physical-chemical properties of the microcapsules (Arshady, 1999a; Scher, 1999; Tsuji, 2001).

\section{Methods usually used in herbicide micro- encapsulation}

Currently, there are hundreds of patented methods for micro-encapsulation; the number will increase with the development of new micro-encapsulation materials and active ingredients requiring specific procedures for micro-encapsulation (Remuñán López and Alonso Fernández, 1997). The methods more frequently used in plaguicide micro-encapsulation may be grouped into three categories (Arshady, 1999a, b):

Chemical methods, interfacial polymerization and polycondensation. A great number of plaguicides have been encapsulated in a great variety of polymers with this technology (Markus, 1996), especially insecticides (Kawada et al., 1993; Scher et al., 1998; Paik, 2006). However, there are problems of toxicity associated with the use of certain monomers and the reduction of formulation stability due to the chemical reactions between the plaguicides and the monomers during storage (Wilkins, 1990).

Physical-chemical methods. These consist of coacervation, extraction-evaporation of the dissolvent and suspension-reticulation. Coacervation allows for the encapsulation of liquids and solid materials, used mostly for obtaining MIC. Recently, coacervation has been used in fungicide encapsulation of ediphenphos (Tsuiji, 2001) and pheromones (Chen et al., 2007). Through the extraction-evaporation of the dissolvent, plaguicides have been encapsulated in diverse polymers such as poly-e-caprolactone, polyarylsulfone, methacrylate, and various types of cellulose (Dowler et al., 1999; Teff and Friend, 1993; Shiomori et al., 2004). However, the results obtained varied considerably according to the type of plaguicide and polymer considered (Dailey et al., 1993; Dailey and Dowler, 1998; Sopeña et al., 2005; 2007a). Suspension-reticulation is the technique most frequently used with agrochemicals; a great variety of plaguicides have been encapsulated in different materials such as alginates, gelatin, cellulose derivatives (such as carboxymethylcellulose) and starch (Fernández-Pérez et al., 2001; Mathew and Kalyanasundaram, 2004; Garrido-Herrrera et al., 2006). 
Physical methods, extrusion, fluid bed coating and atomization. The physical methods described in this section have been used in encapsulating diverse plaguicides (Tefft and Friend, 1993; Beestman, 2003) and biopesticides (Tamez-Gerra et al., 2000; Ghorbani et al., 2005).

\section{Conclusions}

To summarize, the plaguicide industry formulations must fulfill a series of conditions, the most pressing of which are: 1 . Greater safety during manipulation and application of plaguicides, for the environment as well as for those organisms that are not the target of the plaguicides but that may be exposed. 2. Lower prices, lower cost of production and lower cost/execution ratio. This means that it is frequently difficult for the new compounds to satisfy all the requirements. Thus, the development of new plaguicides faces new challenges, as the time and cost of production has increased, demonstrating the need to improve the formulation. Technological innovation will be required in order to render new and pre-existing plaguicides compliant with the current requirements for environmental and human safety.
The development of new plaguicide formulations and new fields of application for the plaguicides already in existence may be comparable to the development of new plaguicides. The cost and time required for the development of new formulations may be even less than that required for the development of new plaguicides. Current resources are directed toward the development of safer plaguicides, for the worker and for the environment, as well as toward more efficient application and formulation technologies. Thus, the development of ingredients that are more active and effective at reduced doses is essential, and systems of controlled herbicide liberation are becoming more important.

\section{Acknowledgements}

The present work was financed by the Spanish Ministry of Education and Science through the REN2003-01509 and AGL2005-00164 investigation projects, by the Junta de Andalucía through an investigation contract (Resolution of May 12, 2006 by the General Secretariat of Universities, Investigation and Technology), and by investigation Project P06-FQM-01909.

\section{Resumen}

F. Sopeña, C. Maqueda y E. Morillo. 2009. Controlled release formulations of herbicides based on microencapsulation. Cien. Inv. Agr. 36(1): 27-42. Annual worldwide losses to weeds are estimated to be approximately $10-15 \%$ of attainable production of the principal food. Therefore, it does not surprise that the worldwide consumption of herbicides is $47.5 \%$ of the 2 million tonnes of pesticide consumption per year. However, the use of herbicides high application rates for yielding good crops has given rise to serious environmental and public health problems. For this reason, the development of new herbicide formulations that are highly effective, safer, for worker and to the environment, and that involve a low cost/production relation becomes important. In this sense, controlled release formulations of herbicides have become more necessary in recent years, since they often enable greater herbicide efficacy, reducing its doses. The present work review in detail both the components and types of herbicide formulations, emphasizing on controlled release formulations from the herbicide microencapsulation (materials and methods) and providing the basic concepts for an adequate comprehension.

Key words: Adjuvants, contamination, control, delivery system, formulations, herbicide, microencapsulation, weed control. 


\section{References}

Albert, L.A. 1998. Los plaguicidas persistentes y sus efectos a largo plazo. II Simposio Internacional Sobre Agricultura Sostenible. México D.F., Mexico (Abstract).

Amber, J. 1994. Microencapsulation. 423-441 pp. In: Encyclopaedia of Pharmaceutical Technology. J. Swarbrick and J.C. Boylan (eds.) Marcel Dekker Inc., NY, USA.

Aminabhavi, T.M., R.H. Balundgi, and P.E. Cassidy. 1990. A review on biodegradable plastics. Polym-Plast. Technol. Eng. 29:235-262.

Ansel, H.C., L.V Allen, and N.G.P. Popovich. 1999. Modified-release dosage forms and drug delivery systems. 229-243 pp. In: Pharmaceutical Dosage Forms and Drug Delivery Systems. Lippincott Williams and Wilkins, Philadelphia, USA.

Arshady, R. (ed.). 1999a. Microspheres, Microcapsules and liposomes: general concepts and criteria. Pages 11-45. In: Microspheres, Microcapsules and Liposomes. Preparation and Chemical Applications. Vol 1. Citus Book Inc., London.

Arshady, R. 1999b. In the name of particle formation. Colloids and Surfaces A: Physicochemical Engineering Aspects 153:325-333.

Barr, D.B., and C.C. Needham. 2002. Analytical methods for biological monitoring of exposure to pesticides: a review. Journal of Chromatography B 778:5-29.

Beestman, G.B. 2003. Controlled release in crop protection: past experience and future potential. 272-279 pp. In: G. Voss and G. Ramos. (ed.). Chemistry of crop protection, progress and prospects in science and regulation. Wiley-VCH Verlag $\mathrm{GmbH} \& \mathrm{Co}$, Weinheim.

Bernards, M.L., J.T.Simmons, C.J Guza., R. Schulz, D. Penner, and J.J. Kells. 2006. Inbred corn response to acetanilide herbicides as affected by safeners and microencapsulation. Weed Techn. 20:458-465.

Berrada, H., G. Font, and J.C. Molto. 2003. Determination of urea pesticide residues in vegetable, soil, and water samples. Crit. Rev. Anal. Chem $33: 19-41$.

Bifani, P. 1987. Socioeconomic Aspects of technological innovation in food production systems. Memorie Di Scienze Fisiche E Naturali. Accademia Nazionale Delle Scienze, Serie V, Vol. XI, Parte II, Roma.
Boparai, H., P. Shea, S. Comfort, and D. Snow. 2006. Dechlorinating chloroacetanilide herbicides by dithionite-treated aquifer sediment and surface soil. Environ. Sci. Technol. 40:3043-3049.

Carter, A.D. 2000. Herbicide movement in soils: principles, pathways and processes. Weed Res. 40:13-122.

Chen Z., Y. Fang, and Z. Zhang. 2007. Synthesis and assessment of attractiveness and mating disruption efficacy of sex pheromone microcapsules for the diamondback moth, Plutella xylostella $\mathrm{L}$. Chinese Sci. Bull. 52:1365-1371.

Codex Alimentarius. Comisión Del Codex Alimentarius. Manual De Procedimiento. Programa Conjunto FAO/OMS Sobre Normas Alimentarias www.Codexalimentarius.Net/Web/Procedural_Manual_Es.Jsp.

Collet, J., and C. Moreton. 2004. Forma farmacéutica oral de liberación modificada. Pages 289305. In: Aulton M.E. (ed.). Farmacia, la ciencia del diseño de las formas farmacéuticas. Elservier España, Madrid.

Cotterill, J.V., and R.M. Wilkins. 1996. Controlled release of phenylurea herbicides from a lignin matrix: release kinetics and modification with urea. J. Agr. Food Chem. 44:2908-2912.

Covas G. 2003. Formulaciones y Adyuvantes. www.Argenpapa.Com.Ar/Img/FORMULACIONES\%20Y\%20COADYUVANTES.Pdf.

Dailey, O.D., and C.C. Dowler. 1998. Polymeric microcapsules of cyanazine: preparation and evaluation of efficacy. J. Agr. Food Chem. 46:38233827.

Dailey, O. 2004. Volatilization of Alachlor from Polymeric Formulations. J. Agric. Food Chem. 54:6742-6746.

Dailey, O.D., C.C. Dowler, and B.G. Mullinix. 1993. Polymeric microcapsules of the herbicides atrazine and metribuzin: preparation and evaluation of controlled-release properties. J. Agr. Food Chem. 41:1517-1522.

Dowler C., O.Dailey, and B. Mullinix. 1999. Polymeric microcapsules of alachlor and metholachlor: preparation and evaluation of controlled-release properties. J. Agric. Food Chem. 47:2908-2913.

Fernández-Pérez, M. 2007. Controlled release systems to prevent the agro-environmental pollution derived from pesticide use. J. Environ. Sci. Health B 42:857-862.

Fernández-Pérez, M., M. Villafranca-Sánchez, F. Flores-Céspedes, and F. Garrido-Herrera. 2005. 
Use of bentonite and actived carbon in controlled release formulations of carbofuran. J. Agric. Food Chem. 53: 6697-6709.

Fernández-Urrusuno, R., J. Ginés, and E. Morillo. 2000. Development of controlled release formulations of alachlor in ethylcellulose. J. Microencapsul. 17:331-342.

Fleming, G.F. L.M. Wax, F.W. Simmsons, and A.S. Felsot. 1992. Movement of alachlor and metribuzin from controlled release formulations in a sandy soil. Weed Sci. 40:606-613.

Gan J., M. Hussain, and M.N. Rathor. 1994. Behaviour of an alginate-kaolin based controlled-released formulation of the herbicide thiobencarb in simulated ecosystems. Pestic. Sci. 42:265272.

García Torres L.,and C. Fernández-Quintanilla (ed.). 1991. Fundamentos sobre malas hierbas y herbicidas. M.A.P.A, Publicaciones del Servicio de Extensión Agraria, Madrid, España. 348 pp.

García, J. 1998. Intoxicaciones agudas por plaguicidas: costos humanos y económicos. Rev. Panam. Salud Pública 4:383-387.

Garrido-Herrera, F.J., E. González-Pradas,and M. Fernández-Pérez. 2006. Controlled release of isoproturon, imidacloprid, and cyromazine from alginate-bentonite-activated carbon formulations. J. Agric. Food Chem. 54:10053-10060.

Geisler G., Hellweg S., Liechti S., and Hungerbüler K. 2004. Variability assessment of groundwater exposure to pesticides and its consideration in life-cycle assessment. Environ. Sci. Technol. 38:4457-4464.

Gerstl, Z., A. Nasser, and U. Mingelgrin. 1998. Controlled release of pesticides into soils from claypolymer formulations. J. Agric. Food Chem. 46:3797-3802.

Ghorbani, R., C. Leifert, and W. Seel. 2005. Biological control of weeds with antagonistic plant pathogens. Advances in Agronomy 86:191-220.

Ginés, J.M., M.J. Arias, J.I Pérez-Martínez, J.R.Moyano, E. Morillo, and P.J. Sánchez-Soto, 1998. Determination of the Stoichiometry of 2,4 Dichlorophenoxyacetic Acid-B-Cyclodextrin Complexes in solution and in solid state. Thermochim. Acta 321:53-58.

González-Rodríguez, M.L., L.B. Barros, J. Palma, P.L. González-Rodríguez, and A.M. Rabasco. 2007. Application of statistical experimental design to study the formulation variables influencing the coating process of lidocaine liposomes. Int. J. Pharm. 337:336-345.
Green J.M., and G.B. Beestman. 2007. Recently patented and commercialized formulation and adjuvant technology. Crop Prot. 26:320-327.

Greene, L.C., P.A. Meyers, J.T. Springer, and P.A. Banks. 1992. Biological Evaluation of Pesticides Released from Temperature-Responsive Microcapsules. J. Agric. Food Chem. 40:2274-2278.

Gupta, P.K. 2004. Pesticide Exposure-Indian Scene. Toxicology 198:83-90.

Hatzinikolaou A.S., I.G. Eleftherohorinos, and I.B. Vasilakoglou. 2004. Influence of Formulation on the Activity and Persistence of Pendimethalin. Weed Technol. 18:397-403.

Kamiya M., K. Kameyama, and S. Ishiwata. 2001. Effects of Cyclodextrins on Photodegradation of Organophosphorus Pesticides in Humic Water. Chemosphere 42: 251-255.

Kawada, H., T. Ohtubo, S. Tsuda, Y. Abe, and K. Tsuji. 1993. Insecticidal characteristics of cyphenothrin microcapsules for cockroach control. Jpn. J. Environm. Entomol. Zool. 5: 65-72.

Kök, F.N., R.M. Wilkins, R.B. Cain, M.Y. Arica, G. Alaeddinoglu, and V. Hasirci. 1999. Controlled release of aldicarb from lignin loaded ionotropic hydrogel microspheres. J. Microencapsul. 16: 613-623.

Konstantinou I., D. Hela, and T. Albanis. 2006. The Status of pesticide pollution in surface wasters (rivers and lakes) of greece. Part I. Review on occurrence and levels. Environ. Poll. 141: 555570.

Kudsk P. and J.C. Streibig. 2003. Herbicides- A Two Edged Sword. Weed Res. 43: 90-102.

Labrada R., J.C. Caseley y C. Parker. 1996. Manejo de malezas para países en desarrollo (Estudio FAO Producción y Protección Vegetal - 120). Departamento de Agricultura. Organización de las Naciones Unidas para la Agricultura y la Alimentación, Roma, Italia.

Lohmann, D.G. 1992. Biodegradable Polymers and additives in agricultural controlled release systems. Proceed. Int. Symp. Contamrol Rel. Bioact. Materials 19; 170-171.

Markus A. 1996. Advances in the technology of controlled-release pesticide formulations. 73-91 pp. In: Benita S. (ed.) microencapsulation: methods and industrial applications. Marcel Dekker, New York.

Mathew, N., and M. Kalayanasundaran. 2004. Development of biodegradable aluminium carboxymethylcellulose matrices for mosquito larvicides. Pest. Manag. Sci. 60: 685-690. 
Mcdonald, D. 2002.The World's Worst Weed. Int. Pest Cont. L. 44: 55-58.

Mills, M.S. and E.M. Thurman. 1994. Reduction of non point-source contamination of surface and groundwater by starch encapsulated atrazine. Environ. Sci. Technol. 28: 73-79.

Morillo, E., R. Fernández-Urrusuno, M.J. Arias, J.I. Pérez-Martínez, and J.M. Ginés. 1998. Study of complexation between the pesticide chlorpyrifos and $\beta$ - and HP- $\beta$-cyclodextrins. Proc. 9th Int. Symp. on Cyclodextrins. Torres Labandeira And Vila Jato (Eds.). Kluwer Academic Publishers: 595-599.

Morillo, E., T. Undabeytia, C. Maqueda, and A. Ramos. 2000. Glyphosate adsorption on soils of different characteristics. Influence of copper addition. Chemosphere 40: 103-107.

Morillo, E. 2006. Application of Cyclodextrins in Agrochemistry. Cyclodextrins and their Complexes. Doolzink H. (Ed.). Wiley-VCH.

Mulqueen, P. 2003. Recent advances in agrochemical formulation. Adv. Coll. Inter. Sci. 106: 83-107.

Mura, P., F. Maestrelli, M.L. González-Rodríguez, I. Michelacci, C. Ghelardini, and A.M. Rabasco. 2007. Development, characterization and in vivo evaluation of benzocaine-loaded liposomes. E. J. Pharm. Biopharm. 67: 86-95.

Nègre, M., M.Gennari, E. Raimomndo, L. Celi, M. Trevisan and E. Capri. 1992. Alachlor dissipation in soil as influenced by formulation in soil moisture. J. Agric. Food Chem. 40: 1071-1075.

Nelson, E.A., and D. Penner. 2007. Leaching Of Isoxaflutole and the Herbicide Safeners R-29148 and Furilazole. Weed Techn. 21: 106-109.

Paik, S. 2006. Environmentally Friendly Polyurea Microcapsules of pesticides by PVA mediated interfacial polymerization. Materials Science Forum 510-511, 678-681.

Parker, D.C., F.W. Simmons, and L.M. Wax. 2005. Fall and early preplant application timing effects on persistence and efficacy of acetamide herbicides. Weed Sci. 19: 6-13.

Pérez-Martinez, J.I., E. Morillo, and J.M. Gines. 1999. $\beta$-Cd Effect On 2,4-D Soil Adsorption. Chemosphere 39: 2047-2056.

Pérez-Martínez, J.I., J.M. Ginés., E. Morillo, M.J. Arias, and J.R. Moyano. 2000b Improvement of the desorption of the pesticide 2,4-D via complexation with HP- $\beta$-Cyclodextrin. Pestic. Sci. 56: 425-430.

Pérez-Martínez, J.I., E.Morillo, C. Maqueda, and J.M. Ginés. 2001. Ethyl cellulose polymer mi- crospheres for controlled release of norflurazon. Pest. Manag. Sci. 57: 688-694.

Petersen, B.B., P.J. Shea, and G.A. Wicks. 1988. Acetanilide activity and dissipation as influenced by formulation and wheat stubble. Weed Sci. 36:243-249.

Prasad, M.P. and M. 1993. Kalyanasundaram Effect of the incorporation of gelatin, an interactive polymer, on the matrix stability and release of fenthion from crosslinked matrices of carboxymethylcellulose. J. Control Release 27: 219-225.

Remuñán-López, C. y M.J. Alonso-Fernández. 1997. Microencapsulación de medicamentos. 577-609 pp. In: Vila Jato J.L. (ed.). Tecnología farmacéutica. Formas farmacéuticas (Vol. I).

Ribeiro, M.L., C. Lourencetti, S. Yoshinaga, M.R., and Rodrigues De Marchi. 2007. Groundwater Contamination by Pesticides: Preliminary Evaluation. Quim. Nova 30: 688-694.

Riggle, B.D., and D. Penner. 1988. Controlled Release of three Herbicides with the Kraft Lignin Pc940c. Weed Sci. 36: 131-136.

Rosales-Robles, E., R. Sánchez-de la Cruz, and J.R. Salinas-García. 2005. Critical period of competition of wild sunflower (Helianthus annus L.) in grain sorghum. Agrociencia 39:205-210.

Rüegg, W.T., M. Quadranti, and A. Zoschke. 2007. Herbicide research and development: challenges and opportunities. Weed Res. 47: 271-275.

Scher, H.B. (ed..). 1999. Controlled-Release Delivery Systems For Pesticides. Marcel Dekker, New York. 329 pp.

Scher, H.B., M. Rodson, and K. Lee. 1998. Microencapsulation of pesticides by interfacial polymerization utilizing isocyanate or aminoplast chemistry. Pest. Sci. 54: 394-400.

Seaman, D. 1990. Trends in the formulation of pesticides -An Overview. Pestic. Sci. 29: 437-449.

Shiomori, K., J. Taniguchi, S. Kiyoyama, Y. Kawano, and H. Hatate. 2004. Preparation and release characteristics of biodegradable microcapsules encapsulating activated carbon impregnated with pesticide using the solvent evaporation method. J. Chem. Eng. Japan 37: 357-364.

Sopeña, F., A. Cabrera, C. Maqueda, and E. Morillo. 2005. Controlled release of the herbicide norflurazon into water from ethylcellulose. J. Agric. Food Chem. 53:3540-3547.

Sopeña, F., C. Maqueda, and E. Morillo. 2007a. Norflurazon mobility, dissipation, activity and persistence in a sandy soil as influenced by formulation. J. Agric. Food Chem. 55:3561-3567. 
Sopeña, F., C. Maqueda, and E. Morillo. 2007b. Ethylcellulose formulations for controlled release of the herbicide alachlor in sandy soil. J. Agric. Food Chem. 55: 8200-8205.

Sopeña, F., C Maqueda, and E. Morillo. 2008a. Influence of soil characteristics and formulation on alachlor dissipation in soil. Soil Sci. Soc. Am. J. 72: $767-774$

Sopeña, F., C Maqueda, and E. Morillo. 2008b. Formulation affecting alachlor efficacy and persistence in sandy soils. Weed Res. (in revision).

Szejtli, J. 1982. Cyclodextrins and their inclusion complexes. Akadémiai Kiadó, Budapest.

Szejtli, J. 1988. Cyclodextrins in pesticides. Cyclodextrins technology. Reidel, Dordrecht.

Tamez-Guerra, P., M.R. Mcguire, R.W. Behle, B.S. Shasha, N. Galá, and L.J. Wong. 2000. Assessment of microencapsulated formulations for improved residual activity of Bacillus thuringiensis. J. Ec. Entomol. 93: 219-225.

Tefft, J., and D. Friend. 1993. Controlled release herbicide formulations based on polymeric microspheres. J. Control. Release 27: 27-35.

Tsuji, K. 2001. Microencapsulation of pesticides and their improved handling safety. J. Microencapsul. 18: 137-147.

Undabeytia, T., S. Nir, and M.J. Gomara. 2004. ClayVesicle interactions: fluorescence measurements and structural implications for slow release formulations of herbicides. Langmuir 20: 66056610 .

Undabeytia, T., Y.G. Mishael, S. Nir, B. Papahadjopoulos-Sternberg, B. Rubin, E. Morillo, and C. Maqueda. 2003. Novel system for reducing leaching from formulations of anionic herbicides: clay-liposomes. Environ. Sci. Techn. 19: 4475-4480.

Vasilakoglou, I.B., I.G. Eleftherohorinos, and K.D. Dhima. 2001. Activity, adsorption and mobility of three acetanilide and two new amide herbicides. Weed Res. 41: 535-546.
Vasilakoglou, I.B., and I:G. Eleftherohorino. 2003. Persistence, efficacy, and selectivity of amide herbicides in corn. Weed Technol. 17: 381-388.

Villafranca-Sánchez, M., E. González-Pradas, M. Fernández-Pérez, F. Martinez-López, F. FloresCépedes, and M.D. Ureña-Amate. 2000. Controlled release of isoproturon from an alginatebentonite formulation: water release kinetics and soil mobility. Pest Manag. Sci. 56: 749-756.

Villaverde, J. 2007. Time-dependent sorption of norflurazon in four different soils: use of $\beta$-Cyclodextrin solutions for Remediation of pesticide-contaminated soils. J. Hazard Mater. 142: 184-190.

Wang, X.Y., and M.L. Brusseau. 1993. Solubilization of some low polarity organic compounds by HP$\beta$-Cd. Environ. Sci. Technol. 27: 2821-2825.

Ware, G.W., and D.M. Whitacre. 2004. The Pesticide Book. 6th Ed. Meister Media Worldwide. Willoughby, Ohio (USA). 526 pp.

Whienhold, B.J., and T. Gish. 1994. Chemical properties influencing rate of release of starch encapsulated herbicides: implications for modifying environmental fate. Chemosphere 28: 10351046.

Wilkins, R.M. (ed.). 1990. Controlled Delivery Of Crop-Protection Agents. Taylor and Francis Ltd., London. UK. 325 pp.

Zabkiewicz, J.A. 2000. Adjuvants and herbicidal efficacy-present status and future prospects. Weed Res. 40: 139-149.

Zhao, J. and R.M. Wilkins. 2000. Controlled Release of an herbicide from matrix granules based on solvent-fractionated organosolv lignins. J. Agric. Food Chem. 48: 3651-3661.

Zhu, Z., and R. Zhuo. 2001. Slow release behaviour of starch-g-poly (vinylalcohol) matrix for 2,4,5trichlorophenoxyacetic acid herbicide. European Polymer J. 37: 1913-1919. 